\title{
Territorialização nacional da Educação do Campo: marcos históricos no Sudeste paraense
}

\author{
Evandro Costa de Medeiros ${ }^{1}$ \\ ORCID: 0000-0002-3478-6297 \\ Glaucia de Sousa Moreno ${ }^{1}$ \\ ORCID: 0000-0003-1375-6985 \\ Maria do Socorro Xavier Batista² \\ ORCID: 0000-0002-7202-1041
}

\section{Resumo}

0 artigo aborda a territorialização nacional da Educação do Campo no Brasil com foco na implementação dos cursos de Licenciatura em Educação do Campo (LEDoC), em especial nas Instituições Federais de Ensino Superior (IFES). Buscou-se compreender a política nacional de expansão e territorialização desses cursos, refletindo acerca de ações e implementação de programas em Educação do Campo desde o protagonismo dos movimentos sociais e da territorialização nacional dos cursos de Licenciatura em Educação do Campo (LEDoC). A fonte privilegiada da pesquisa é o Censo da Educação Superior, publicado em 2017 pelo Instituto Nacional de Estudos e Pesquisas Educacionais (INEP). Historicizou-se o processo de constituição das ações e programas em Educação do Campo, destacando-se os efeitos da política nacional de expansão da LEDoC no Sudeste do Pará, onde foi criada a primeira Faculdade de Educação do Campo do país, vinculada à Universidade Federal do Sul e Sudeste do Pará (UNIFESSPA) e que, nacionalmente, tem o maior número de alunos matriculados no curso. Foram analisados dados dos 40 cursos, executados por 27 Instituições Federais de Ensino Superior (IFES), distribuídos entre capitais e municípios do interior de 17 estados brasileiros, mais o Distrito Federal.

\section{Palavras-chave}

Educação do campo - Políticas públicas - Formação de educadores.

1- Universidade Federal do Sul e Sudeste do Pará, Marabá, PA, Brasil. Contatos: evandromedeiros1973@gmail.com; gs.moreno1@gmail.com.

2- Universidade Federal da Paraíba, João Pessoa, PB, Brasil. Contato: socorroxbatista@gmail.com. 


\section{National Territorialization of Rural Education: Historical landmarks in Southeast Pará*}

\section{Abstract}

This article discusses the national territorialization of Education in Brazilian rural areas. The focus here is on the implementation of a Degree in Rural Education (LEDoC), especially in Federal Institutions of Superior Education (IFES). This paper is looking for the understanding of the national policy of expansion and territorialization of these courses by reflecting on actions and implementation of programs in this kind of Education from the protagonism of social movements and the national territorialization of the Teaching Degree in Rural Education (LEDoC). The privileged source of research is the Superior Education Census, published in 2017 by the National Institute of Educational Studies and Research (INEP). The process of constitution of actions and programs in Education in rural areas was historicized, highlighting the effects of the national policy of expansion of LEDoC in Southeast Pará, where the first Brazilian Faculty of Rural Education, linked to the Federal University of the South and Southeast of Pará (UNIFESSPA), was created. Nationally, this faculty has the largest number of students enrolled in the course. Data from 40 courses, run by 27 Federal Institutions of Superior Education (IFES), distributed between capitals and cities in the interior of 17 Brazilian states, plus the Federal District, had been analyzed.

\section{Keywords}

Rural Education - Public policies - Training of educators.

\section{Introdução}

Este artigo foi elaborado com intuito de superar contradições no uso de dados em publicações recentes e diversas acerca dos cursos de Licenciatura em Educação do Campo (LEDoC) em funcionamento no país. As contradições manifestam-se nas tentativas de distintos autores em configurar a descrição nacional sobre o curso a partir do Censo da Educação Superior, publicado em 2017 pelo Instituto Nacional de Estudos e Pesquisas Educacionais (INEP). A análise de artigos acadêmicos produzidos a partir de tais dados permitiu a constatação do uso de números diferentes para representar o mesmo universo de cursos da LEDoC realizados dentro de um mesmo período. A caracterização da LEDoC nessas produções restringe-se sempre aos cursos vinculados ao Programa Nacional de Educação do Campo (PRONACAMP0), criados por meio de Edital em 2012, que permitiu a implementação de 40 cursos, executados por 27 Instituições Federais de Ensino Superior (IFES). Em alguns artigos, os números apresentados diferem-se dessa totalização.

Ocorre ainda a omissão de dados a respeito de cursos da LEDoC criados em 2008 e 2009 pelos editais do Programa de Apoio à Formação Superior em Licenciatura em 
Educação do Campo ${ }^{3}$ (PROCAMPO), que se encontram em funcionamento com oferta de turmas contínuas, mas que não estão vinculados ao PRONACAMPO. Além disso, tais artigos não explicitam a existência de turmas do curso LEDoC implementadas na modalidade de Educação à Distância e de cursos criados por iniciativas de IES com recursos próprios e/ ou pelo Programa de Reestruturação e Expansão das Universidades (REUNI).

Nesse contexto, além de buscar socializar dados acerca das diferentes formas de oferta do curso como marco da territorialização nacional da rede político-pedagógica que conforma o Movimento de Educação do Campo, o presente trabalho objetiva ainda apresentar dados a respeito do curso da LEDoC, realizado desde 2009 no Sudeste do Pará. Busca, assim, contribuir com a sistematização, análise e reflexão acerca da trajetória histórica do curso e das conquistas que se consolidam a partir de sua implementação localmente.

0 artigo está estruturado em três seções. A primeira traz reflexões acerca do surgimento do Movimento Nacional em Educação do Campo à consolidação do curso de LEDoC; a segunda trata da política de expansão dos cursos de LEDoC no Brasil; enquanto a terceira apresenta o curso de LEDoC da Faculdade de Educação do Campo, da Universidade Federal do Sul e Sudeste do Pará.

\section{O movimento nacional por uma Educação do Campo}

O Movimento de Educação do Campo nasceu no final dos anos de 1990 durante o I Encontro Nacional de Educadores da Reforma Agrária (ENERA), realizado em Brasília, em julho de 1997. 0 evento foi fruto de uma parceria entre o Grupo de Trabalho de Apoio à Reforma Agrária da Universidade de Brasília (GT-RA/UnB), o Movimento dos Trabalhadores Rurais Sem Terra (MST), representado pelo seu Setor de Educação, além do Fundo das Nações Unidas para a Infância (UNICEF), do Fundo das Nações Unidas para a Ciência e Cultura (UNESCO) e Confederação Nacional dos Bispos do Brasil (CNBB). Outro evento importante para impulsionar o movimento foi a I Conferência Nacional Por uma Educação Básica do Campo, ocorrida em Luziânia, Goiás, em julho de 1998, evento organizado pela Articulação Nacional por uma Educação Básica do Campo.

Esses eventos afırmaram a compreensão da luta pela terra e por Reforma Agrária em sentido amplo, integrando a luta pela garantia do direito à educação aos povos. 0 debate sobre a Educação do Campo trouxe para a educação a discussão acerca de contradições históricas decorrentes da questão agrária no Brasil. Trouxe também o anúncio do campo como território de possibilidades em que sujeitos diversos constroem cotidianamente, ao seu modo, conhecimentos e estratégias de produção material e nãomaterial necessárias à manutenção da vida coletiva, familiar, comunitária, o campo como território de existências e riquezas sociais, culturais e políticas. 0 campo como território de vida, produção, saberes e culturas expressa-se em uma diversidade de comunidades de agricultores familiares, pescadores, indígenas, quilombolas e também na existência de cidades pequenas, cuja dinâmica social não se contrapõe às comunidades rurais,

3- Edital $n^{0}$ 2, de 23 de abril de 2008, Chamada Pública para seleção de projetos de instituições públicas de ensino superior para o Procampo e Edital de Convocação № 09, DE 29 de abril de 2009. 
mas com ela dialeticamente mantém inter-relação, desencadeando processos de mútua influência cultural, política, econômica.

Defendeu-se que a educação escolar como uma conquista provinda das lutas por direitos não pode ser para o homem no campo, mas com e do homem do campo, onde estejam assegurados o protagonismo pedagógico e o diálogo com os saberes e práticas culturais dos educadores, educandos e comunidades camponesas, consideradas um lugar-sujeito coletivo de produção de conhecimentos. Trata-se de uma educação própria dos povos do campo que vá além do mero adequar a escola à necessidade de escolarizar o trabalhador rural e/ou assegurar formas legais de adaptação curricular para adequar conteúdos e metodologias às especificidades locais, algo já previsto no movimento do ruralismo pedagógico décadas atrás, como meio para fixar o homem rural ao rural.

Nesse aspecto, uma das principais conquistas dos movimentos sociais do campo no final dos anos de 1990 foi a criação do Programa Nacional de Educação na Reforma Agrária (PRONERA), resultado das proposições feitas durante o I Encontro Nacional de Educadores da Reforma Agrária (ENERA). Criado em abril de 1998, o PRONERA, como um programa federal, sob gerência do Instituto Nacional de Colonização e Reforma Agrária (INCRA), foi proposto para ser executado por uma ampla articulação interinstitucional, que envolve Estado, universidades e movimentos sociais, tendo como objetivo geral fortalecer a educação nos assentamentos de modo a estimular, propor, criar, desenvolver e coordenar projetos educacionais, utilizando metodologias específicas para o campo (SILVA, 2006, p. 86).

A proposição e execução de projetos de cursos via PRONERA revigoraram a parceria que havia permitido a realização do ENERA e da Conferência Nacional por uma Educação Básica do Campo, fortalecendo e ampliando a relação entre movimentos sociais do campo e universidades, organizações não-governamentais e setores religiosos progressistas, inaugurando uma rede nacional de iniciativas pedagógicas em diferentes níveis de ensino e modalidades educativas que inspirariam a criação de outras ações e programas em Educação do Campo por todo o país.

Uma característica importante no processo de constituição do Movimento da Educação do Campo é como as diferentes práticas educativas vão se articulando e constituindo diferentes "redes políticas e de aprendizagens" constituindo uma base conceitual para a prática a partir das experiências que se desenvolviam na educação escolar e não escolar. (SILVA, 2009, p. 144).

A execução do PRONERA fomentou a constituição de uma "rede nacional para realização de cursos" (IPEA, 2015), provocando a maior aproximação dos movimentos sociais do campo e as universidades, que atuariam como instituições parceiras proponentes dos projetos. No período de 1998 a 2011, o PRONERA promoveu no país 320 cursos, sendo 167 de EJA (Educação de Jovens e Adultos) fundamental, 99 de nível médio e 54 de nível superior. Atendeu 164.894 educandos, sendo 154.192 atendidos pela EJA, 7.379 alunos no ensino médio e 3.323 formados em nível superior. Envolveu 13.276 educadores, 82 instituições de ensino, 38 organizações demandantes e 244 parceiros (IPEA, 2015). 
Figura 1- Municípios de realização dos cursos do PRONERA por nível (1998-2011)

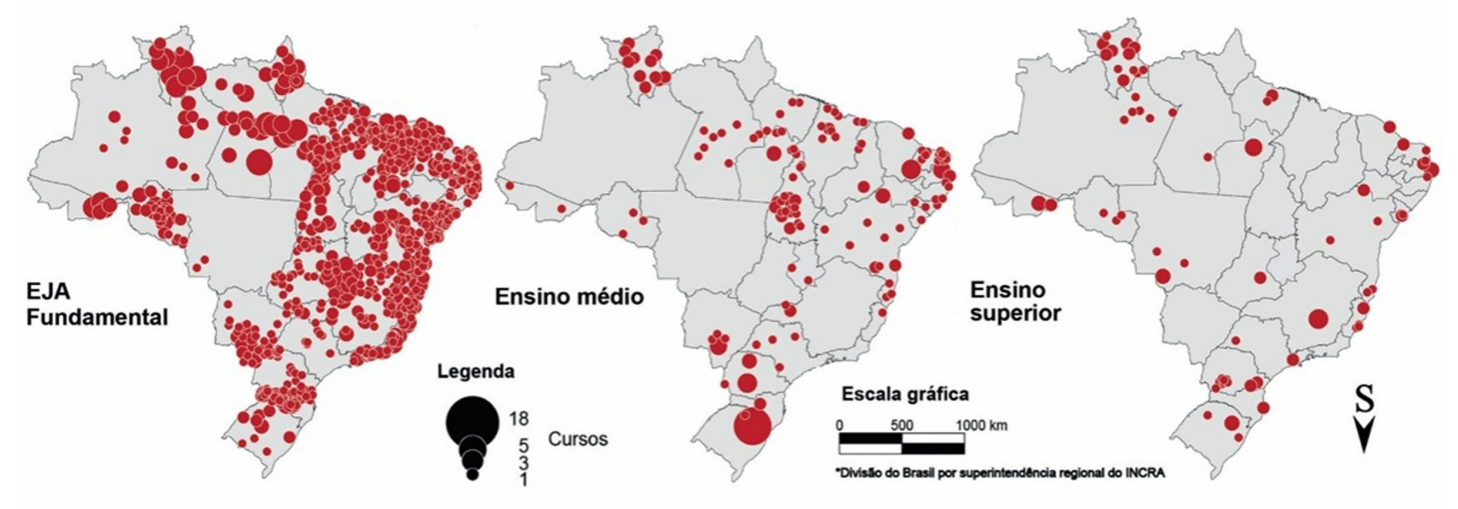

Fonte: IPEA, 2015.

Por meio PRONERA, os movimentos sociais do campo, enquanto sociedade civil organizada, passaram a protagonizar junto às universidades a elaboração e execução de projetos educacionais em diferentes níveis e modalidades, desencadeando a territorialização nacional da Educação do Campo e do movimento que a constitui, que logo se afirmou como uma potente rede política de interlocução com Estado e formulação de propostas para transformação da Educação do Campo em política pública.

Entre 2004 e 2010, multiplicaram-se eventos acadêmicos e pedagógicos nos âmbitos municipal, estadual e nacional voltados ao debate sobre a Educação do Campo, entre eles ganharam destaques os Seminários Estaduais de Educação do Campo, organizados pela parceria entre universidades, movimentos sociais e a Coordenação Geral de Educação do Campo (SECAD/MEC), que objetivaram discutir e levantar proposições para as bases de uma política pública em educação do campo no Brasil. Nesse mesmo período, são expressões das conquistas dos processos e debates levados a cabo pelo Movimento Nacional de Educação do Campo a criação da Coordenação Geral de Educação do Campo no âmbito da Secretaria de Educação, Continuada, Alfabetização e Diversidade (SECAD/ MEC), em 2004, e a elaboração e aprovação das Diretrizes Operacionais para Educação Básica nas Escolas do Campo (Resolução CNE/CEB n 1, de 03 de abril de 2002), que pressupõe a responsabilidade dos sistemas de ensino em relação à oferta de escolarização aos sujeitos do campo sob a ótica do direito; o respeito às diferenças e da diversidade como estratégia de uma política de igualdade; e o encaminhamento prático de medidas de adequação da escola a vida e demandas dos povos do campo.

Na constituição de espaços de interlocução e influência sobre as políticas públicas, também é reflexo das conquistas do Movimento Nacional de Educação do Campo a criação da Comissão Nacional de Educação do Campo, junto ao Ministério da Educação (Portaria 1258, 19 de dezembro de 2007).

0 movimento de educação do campo ganhou capilaridade nacional efetiva durante dois anos de um processo de construção de propostas de políticas públicas, programas de governos etc., 
numa interação entre as três esferas do Estado e as organizações e movimentos sociais do campo situados nos estados e municípios. (MUNARIM, 2008, p. 12).

Mas foi a criação do Fórum Nacional de Educação do Campo (FONEC), em 2010, a partir da rearticulação e ampliação da frente envolvida na Articulação Nacional por uma Educação do Campo, que consolidou a figura de um sujeito coletivo nacional com representatividade nas relações institucionais e políticas frente ao Estado para defender proposições para a elaboração e implementação de uma política pública em Educação do Campo.

[0 FONEC tem como objetivo] o exercício da análise crítica constante, severa e independente acerca de políticas públicas de Educação do Campo; bem como a correspondente ação política com vistas à implantação, à consolidação e, mesmo, à elaboração de proposições de políticas públicas de Educação do Campo. (FONEC, 2010, p. 1).

Para atender à reivindicação dos movimentos sociais do campo pela ampliação das ações governamentais em Educação do Campo, a Coordenação Geral de Educação do Campo (SECAD/MEC) criou programas inspirados nas experiências do PRONERA, como o Programa Saberes da Terra (2005) e os Cursos de Licenciatura Plena em Educação do Campo (2008), ambos de atendimento à população do campo amplamente e não somente beneficiários da reforma agrária, como no caso do PRONERA. 0 primeiro, Saberes da Terra - Programa Nacional de Educação de Jovens e Adultos para Agricultores/as Familiares integrada com Qualificação Social e Profissional, tem como finalidade proporcionar formação integral, prioritariamente ao jovem do campo, por meio de elevação de escolaridade, tendo em vista a conclusão do ensino fundamental (BRASIL, 2005, p. 10). Já a LEDoC visou à formação de professores em nível superior, habilitados por área de conhecimento para atuarem nos anos finais do Ensino Fundamental e no Ensino Médio e na gestão de processos educativos escolares e processos educativos comunitários.

A partir 2012, os cursos de Licenciatura em Educação do Campo - LEDoC passaram a ser implementados no âmbito do Programa de Apoio à Formação Superior em Licenciatura em Educação do Campo (PROCAMP0), que se constitui como política de formação de educadores, conquistada a partir da pressão e das demandas apresentadas ao Estado pelos movimentos sociais, a partir do Decreto $n^{0} 7.352 / 2010$, que instituiu a Política Nacional de Educação do Campo (MOLINA; HAGE, 2016, p. 804).

\section{O curso de licenciatura em Educação do Campo - LEDoC}

A criação do curso de Licenciatura em Educação do Campo (LEDoC) faz parte de uma ação mais ampla do Ministério da Educação (MEC), iniciada em 2003, para promoção da Política Nacional de Educação do Campo. Essa política veio 
sendo formulada até 2018 pela Secretaria de Educação Continuada, Alfabetização, Diversidade e Inclusão (SECADI), através da Coordenação Geral de Educação do Campo (CGED) e do Grupo de Trabalho Permanente de Educação do Campo (GPT).

A proposta de criação da LEDoC, de modo geral, visa à qualificação acadêmica e profissional de professores para atuarem na educação básica em escolas do campo, de modo a garantir formação escolar às populações do campo de todo país: agricultores familiares, extrativistas, pescadores artesanais, ribeirinhos, assentados e acampados da reforma agrária, trabalhadores assalariados rurais, quilombolas, caiçaras, indígenas, caboclos e outros que produzam suas condições materiais de existência a partir do trabalho no meio rural. Por Escola do Campo entende-se aquela situada em área rural, conforme definida pela Fundação Instituto Brasileiro de Geografia e Estatística (IBGE), ou aquela situada em área urbana, desde que atenda predominantemente a populações do campo (BRASIL, 2010).

A primeira turma de LEDoC foi ofertada pela Universidade Federal de Minas Gerais, em 2005, sendo considerada turma de projeto e instalou-se via parceria entre a Faculdade de Educação da Universidade Federal de Minas Gerais (FaE/UFMG), MST, INCRA e PRONERA. A UFMG voltou a ofertar mais uma turma em 2008, por meio do Edital 2008 SECAD/MEC, citado a seguir. A partir de 2009, o curso foi considerado regular e contou com apoio do REUNI para se estruturar, passando a ofertar 35 vagas anualmente. Segundo dados do INEP (2017), o curso ainda está em funcionamento e em 2017 apresentava 169 alunos matriculados entre ingressantes e concluintes (INEP, 2017).

Em 2007, o MEC, por intermédio da SECADI, criou o Programa de Apoio à Formação Superior em Licenciatura em Educação do Campo (PROCAMP0), que teve como objetivo principal apoiar a implementação de cursos regulares de LEDoC nas IES de todo país, com intuito de promover a formação de professores por área do conhecimento para atuarem nos anos finais do ensino fundamental, ensino médio e gestão dos processos pedagógicos em escolas do campo. Tal programa propiciou a elaboração de dois editais (SECAD/ $\mathrm{MEC} / 2008$ e SECAD/MEC/2009), convocando Instituições de Ensino Superior (IESs) para ofertarem cursos regulares de LEDoC, o que proporcionou a criação de 31 novos cursos nos anos de 2008 e 2009.

Das instituições citadas no Quadro 1, algumas continuaram a ofertar curso de LEDoC até 2017, entre elas: Universidade Federal de Minas Gerais (UFMG), campus Pampulha, com 169 alunos matriculados, Universidade Regional do Cariri (URCA), campus de Crato, com 38 alunos matriculados. Cabe destacar que as instituições supracitadas ofertam curso regular de LEDoC a partir de 2009 via edital do PROCAMPO e com apoio do REUNI, que garantiu a estruturação do corpo docente para atuar no curso. A Universidade Federal de Campina Grande (UFCG), campus de Sumé, criou a LEDoC, em 2009, pelo REUNI, e tinha 102 alunos matriculados, em 2017 (INEP, 2017). 
Quadro 1- Instituições de Ensino Superior que ofertaram Licenciatura em Educação do Campo, a partir dos editais 2008 e 2009- SECADI/MEC - PROCAMPO

\begin{tabular}{|c|c|c|}
\hline Região & Universidades & Estados \\
\hline Centro-0este & UNB & Distrito Federal \\
\hline Nordeste & $\begin{array}{l}\text { UFS, UFPI, UNEB, UFBA, UECE, URCA UFPE, AESET, } \\
\text { UNIVASP, CESA, UFMA, IFMA, UFCG, UNEAL }\end{array}$ & $\begin{array}{c}\text { Sergipe, Piauí, Bahia, Ceará, Pernambuco, Maranhão, } \\
\text { Paraíba e Alagoas }\end{array}$ \\
\hline Norte & UFPA, IFPA, UNIR, UNIFAP, UFRR & Pará, Rondônia, Amapá e Roraima \\
\hline Sudeste & $\begin{array}{l}\text { ISES, UFES, UNIMONTES, UFMG, UFVJM, INFNET, } \\
\text { UNITAU }\end{array}$ & Espírito Santo, Minas Gerais, Rio de Janeiro e São Paulo \\
\hline Sul & UNICENTRO, UNIOESTE, UFTPR, UFSC & Paraná e Santa Catarina \\
\hline
\end{tabular}

Fonte: SECAD, 2012

Destarte, no ano de 2010 foi publicado o Decreto № 7.352, de 4 de novembro de 2010, que institui a Política Nacional de Educação do Campo, o que em certa medida proporcionou a revisão do PROCAMPO e a criação do Programa Nacional de Educação do Campo (PRONACAMPO), cujo objetivo foi oferecer apoio financeiro e técnico para a viabilização de políticas no campo. A implementação do PRONACAMPO, por sua vez, possibilitou a publicação do Edital n ${ }^{\circ}$ 02/2012 da SECADI/MEC, que resultou na seleção de 44 propostas de cursos de LEDoC, porém quatro Instituições de Ensino Superior (IES) contempladas não implementaram o curso, são elas: UFPB, IFMT (Campus Vicente da Serra), IFMG (Norte de Minas), IFSC (Campus Canoinhas).

Os editais de 2008 e 2009 não previam a continuidade da oferta de cursos de LEDoC, logo, muitas das IES citadas acima, participantes desses editais, ofertaram apenas uma turma do curso, ao passo que há instituições que seguem ofertando o curso até os dias atuais. 0 edital de 2012, ao contrário, previa a continuidade da oferta do curso com apoio financeiro ao longo de três anos e dentro de uma perspectiva de política estruturante de formação de educadores. O PRONACAMPO possibilitou ainda a disponibilização de 600 vagas permanentes para docentes e 126 técnicos para as instituições executoras da LEDOC, tendo como meta de formar 15 mil professores para atuar na Educação Básica, nas escolas do campo, nos primeiros três anos dos cursos.

Com o PRONACAMPO, pode-se dizer que ocorreu a consolidação da expansão/ territorialização nacional dos cursos de LEDoC, com a implementação de 40 cursos, executados por 27 Instituições Federais de Ensino Superior (IFES), distribuídos entre capitais e municípios do interior de 17 estados brasileiros, mais o Distrito Federal (INEP, 2017), alcançando todas as cinco regiões do país. 
Quadro 2- Distribuição Nacional das IFES que ofertam a LEdoC via PRONACAMPO (Edital 02/2012, SECADI/MEC)

\begin{tabular}{|c|c|c|}
\hline Região & Universidades & Estados \\
\hline Centro-Oeste & UNB, UFG, UFMS e UFGD & Distrito Federal, Goiás, Mato Grosso do Sul \\
\hline Nordeste & UFPI, UFRB, IFMA, UFMA e UFERSA & Piauí, Bahia, Maranhão, Rio Grande do Norte \\
\hline Norte & UFPA, UNIR, UFRR, UNIFAP, UFT e UNIFESSPA & Pará, Rondônia, Amapá, Roraima e Tocantins \\
\hline Sudeste & UFF, UFES, UFRRJ, UFVJM, UFTM & Rio de Janeiro, Espírito Santo e Minas Gerais \\
\hline Sul & $\begin{array}{l}\text { UFRGS, FURG, UFSC, UTFPR, UNIPAMPA, UFFS e } \\
\text { IFFarroupilha }\end{array}$ & Paraná, Santa Catarina e Rio Grande do Sul \\
\hline
\end{tabular}

Fonte: Censo da Educação Superior - INEP, 2017.

Segundo dados do Censo da Educação Superior, realizado pelo INEP, em 2017 existiam 8.582 alunos vinculados aos cursos da LEDOC, estando inclusos nesse universo os alunos remanescentes dos anos anteriores, alunos concluintes (apenas em fase de elaboração de Trabalho de Conclusão de Curso) e alunos ingressos em 2017. A maior concentração de matrículas está na região norte do país, sendo a Universidade Federal do Sul e Sudeste do Pará, com 446 alunos vinculados, nacionalmente a universidade que concentra o maior número de alunos matriculados na LEDOC (INEP, 2017).

Quadro 3 - Distribuição Nacional de Estudantes Matriculados na LEdoC

\begin{tabular}{|c|c|c|}
\hline Região & Estudantes Vinculados & $\%$ \\
\hline Centro-Oeste & 770 & $9 \%$ \\
\hline Nordeste & 2251 & $26 \%$ \\
\hline Norte & 2609 & $30 \%$ \\
\hline Sudeste & 1426 & $17 \%$ \\
\hline Sul & 1526 & $18 \%$ \\
\hline Total & 8582 & $100 \%$ \\
\hline
\end{tabular}

Fonte: Censo da Educação Superior - INEP, 2017. 
Figura 2- Distribuição Nacional das Instituições de Ensino Superior que ofertam a LEDoC

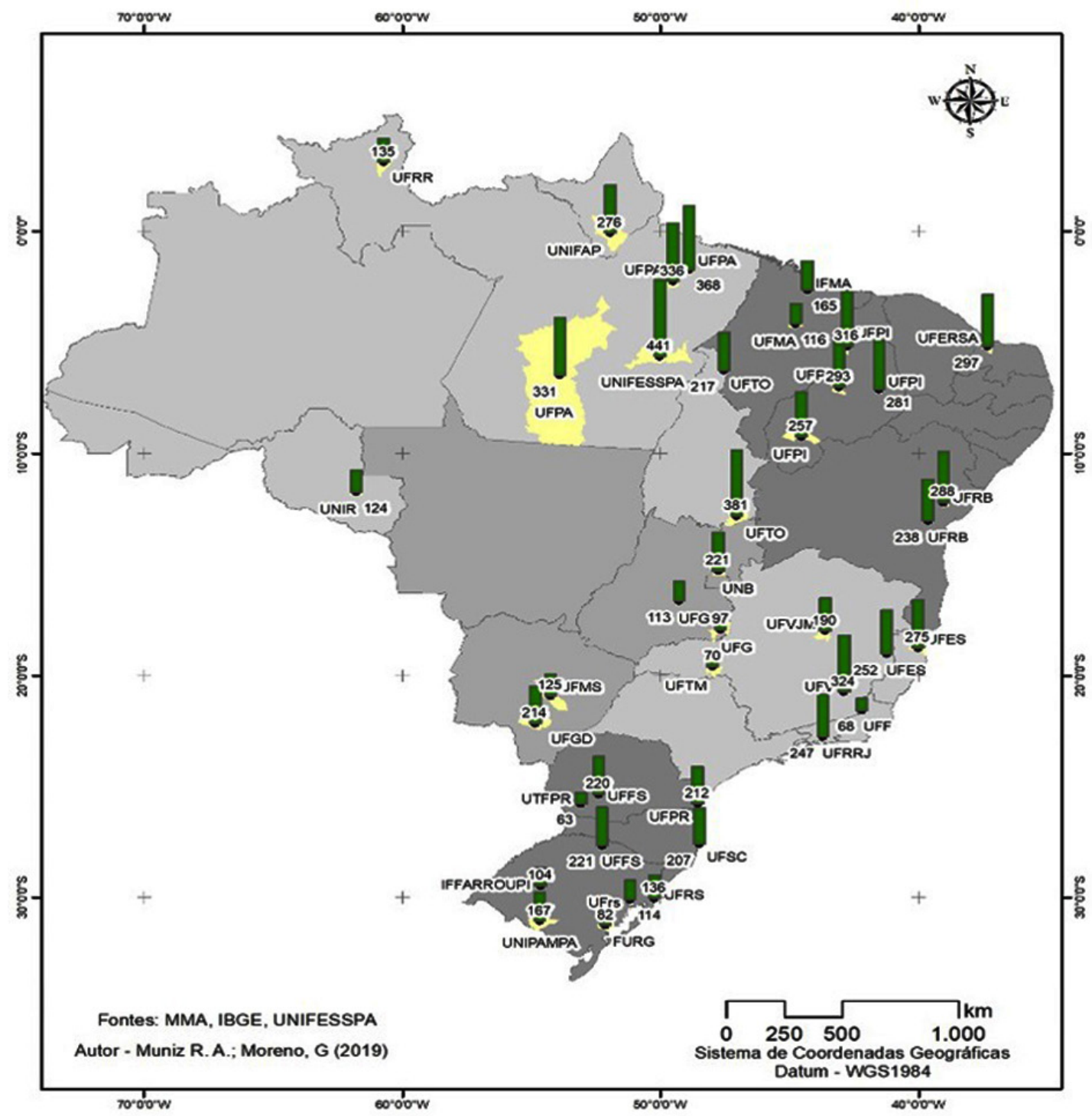

Fonte: MMA, IBGE, UNIFESSPA / Autor (MUNIZ, 2019).

Ainda segundo os dados apresentados pelos INEP (2017) no Censo da Educação Superior, existem cursos de LEDoC que funcionam na modalidade de Educação à Distância. São seis cursos funcionando no estado do Rio Grande do Sul em duas instituições de ensino superior distintas (mais detalhes ver quadro 4). 
Quadro 4- Cursos de LEdoC que funcionam à distância

\begin{tabular}{cccc}
\hline Município & Instituição & No $^{\circ}$ estudantes matriculados & Ano início de funcionamento \\
\hline Seberi & UFSM & 28 & 2017 \\
\hline Cerro Largo & UFSM & 38 & 2017 \\
\hline São Sepé & UFSM & 30 & 2017 \\
\hline Agudo & UFSM & 30 & 2017 \\
\hline Itaqui & UFSM & 30 & 2017 \\
\hline $\begin{array}{c}\text { Sant'Ana do } \\
\text { Livramento }\end{array}$ & UFPEL & 27 & 2009 \\
\hline
\end{tabular}

Fonte: Censo da Educação Superior - INEP, 2017.

Outro dado que merece atenção trata acerca da procedência de formação escolar no ensino médio dos alunos que estão matriculados nos quarenta cursos de LEDoC em funcionamento criados pelo PRONACAMPO. A partir dos dados publicados pelo INEP (2017), constata-se que do total de 8.505 alunos dos cursos a maioria é egressa de escolas públicas, 5.842 (55\%), mas há um quantitativo expressivo de alunos oriundos da rede privada de ensino, totalizando 2.663 (45\%) alunos.

Gráfico 1- Procedência dos Alunos LEDoC - cursos PRONACAMPO

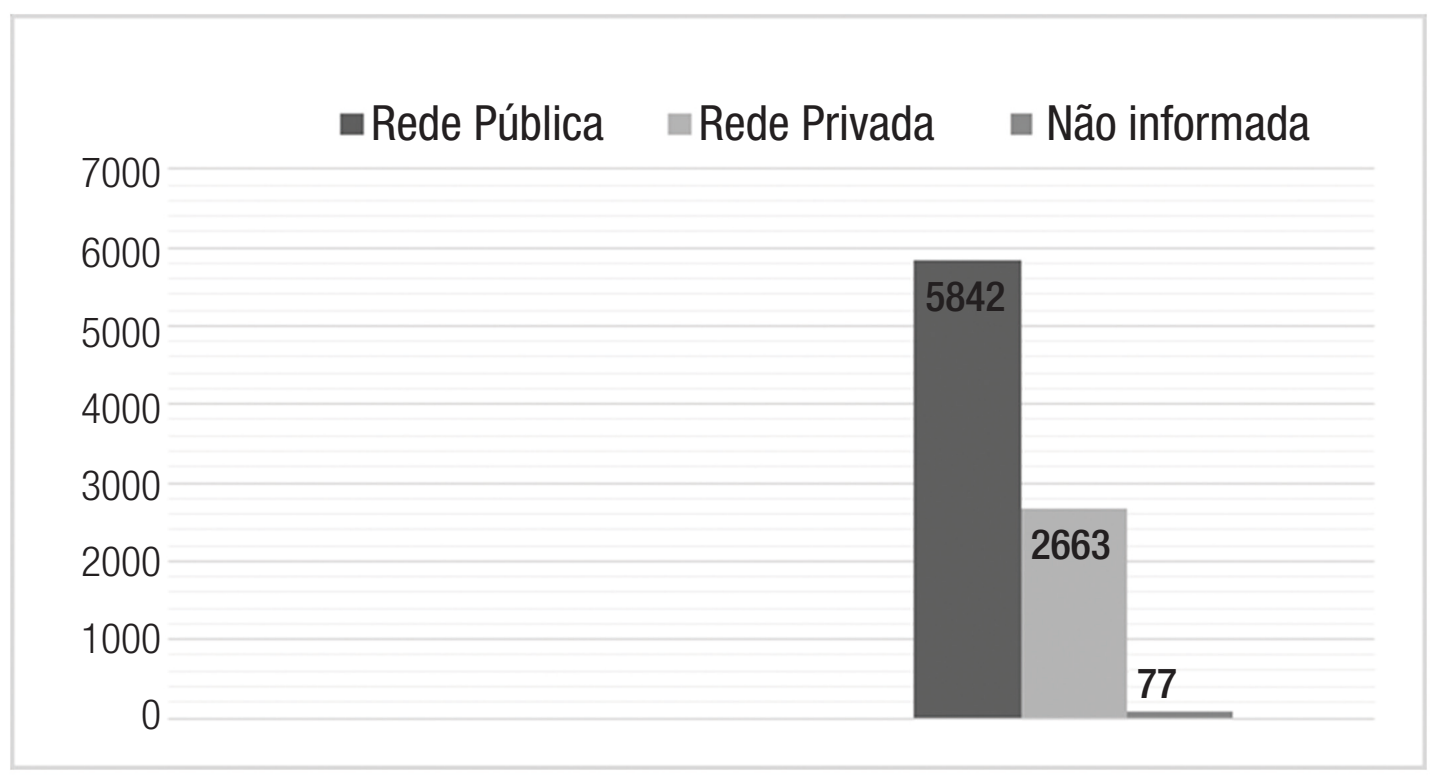

Fonte: Censo da Educação Superior - INEP, 2017. 
Este último dado talvez justifique os motivos que levaram cursos de LEDoC em algumas universidades a realizar o ingresso dos alunos via Processo Seletivo Especial (PSE), que acontece em duas etapas. A primeira é uma prova com quarenta questões de múltipla escolha sobre conhecimentos gerais referentes aos conteúdos programáticos do ensino médio e mais uma redação, já a segunda etapa é qualitativa e conta com realização de entrevistas presenciais em que é verificada a relação do candidato com o curso ou ainda via memorial descritivo do candidato, o que evita ingressos de alunos que não têm vínculo algum com o campo e/ou que cursaram ensino médio em escola privada.

0 cenário de expansão massiva dos cursos da LEDoC faz surgir a preocupação e necessidade de análise e debate acerca de sua oferta segundo pontos basais para execução dos objetivos que lhes deram origem, que em certa medida são colocados em contradição pelos dados expostos no quadro 4 e no gráfico 1. Tais dados representam uma realidade que se distancia do estabelecido pelo artigo $1^{\circ}$ do Decreto 7.352/2010, que dispõe sobre a política de Educação do Campo e o Programa Nacional de Educação na Reforma Agrária:

Art. 1ํ A política de educação do campo destina-se à ampliação e qualificação da oferta de educação básica e superior às populações do campo, e será desenvolvida pela União em regime de colaboração com os Estados, o Distrito Federal e os Municípios, de acordo com as diretrizes e metas estabelecidas no Plano Nacional de Educação e o disposto neste Decreto.

$\S 1$ 1 Para os efeitos deste Decreto, entende-se por:

I - populações do campo: os agricultores familiares, os extrativistas, os pescadores artesanais, os ribeirinhos, os assentados e acampados da reforma agrária, os trabalhadores assalariados rurais, os quilombolas, os caiçaras, os povos da floresta, os caboclos e outros que produzam suas condições materiais de existência a partir do trabalho no meio rural; e

II - Escola do campo: aquela situada em área rural, conforme definida pela Fundação Instituto Brasileiro de Geografia e Estatística - IBGE, ou aquela situada em área urbana, desde que atenda predominantemente a populações do campo. (BRASIL, 2010).

Por fim, a materialização nacional da oferta regular dos cursos da LEDoC incrementou ainda mais a rede político-pedagógica de Educação do Campo envolvendo universidades, movimentos sociais e ONGs e que aproxima secretarias e órgãos de governos municipais e dos estados, constituindo-se em um elemento fundamental à configuração e execução de políticas públicas em educação mais coerentes com a realidade e garantia dos direitos sociais da população do campo.

Assim, além de possibilitar e garantir à população do campo o acesso ao ensino superior, na medida em que a formação de professores para atuarem em escolas do campo ocorre segundo os princípios filosóficos, políticos e pedagógicos da Educação do Campo e considerando os diferentes sujeitos e as diferentes formas de organização da vida e das lutas existentes no país, a materialização dos cursos da LEDoC, territorializados nacionalmente, ajudam no avanço da afırmação de políticas sociais que garantam a universalização de direitos como elemento fundamental da consolidação do Estado democrático (ROCHA, 2013). 


\section{O curso de licenciatura em Educação do Campo no Sudeste do Pará}

Ao tratar da história de criação do Curso de Licenciatura em Educação do Campo da Universidade Federal do Sul e Sudeste do Pará (UNIFESSPA) e da proposta de formação de professores através dele desenvolvida, é preciso compreender o contexto social em que ele se insere, reconhecer a importância neste processo do Programa Nacional de Educação na Reforma Agrária - PRONERA e considerar a atuação da rede político-pedagógica em Educação do Campo que se engendra com a execução deste programa na região.

O PRONERA foi fundamental para emergência e mobilização da Rede PolíticoPedagógica em Educação do Campo paraense. Em âmbito nacional, entre as instituições de ensino superior com maior número de cursos realizados via PRONERA, no período 1998-2011, a Universidade Federal do Pará (UFPA) aparece como a universidade com maior número de projetos realizados, totalizando 31 projetos. Em seguida, estão o Instituto Técnico de Capacitação e Pesquisa da Reforma Agrária (ITERRA) do Rio Grande do Sul, com 18 cursos; a Universidade Federal da Paraíba (UFPB), com 14 cursos; e, com 10 cursos cada uma, a Universidade do Estado da Bahia (UNEB) e a Fundação Universidade do Tocantins (UNITINS) (BRASIL, II Pnera, 2015, p. 46).

Em relação aos cursos do PRONERA realizados no Pará pela UFPA, o maior percentual concentra-se na execução de cursos voltados à formação de professores (32\%), sendo 16\% em nível superior e 16\% em nível médio (técnico em magistério). Em segundo lugar destacam-se os cursos profissionalizantes técnico em agropecuária integrados ao ensino médio, que totalizam 20\% do total dos cursos ofertados pelo programa no estado (BRASIL, II Pnera, 2015). Grande parte desses projetos foi realizada na região Sul e Sudeste do estado, uma das regiões de maior concentração da população assentada pela reforma agrária do norte do país.

Tomada pelos militares no poder após Golpe de Estado de 1964 como "terra sem homens para homens sem-terra" e região de grande potencial em recursos naturais que deveria ser integrada plenamente ao território nacional, o Sul e Sudeste do Pará foi a fronteira para onde se deslocaram entre os anos de 1970 e 1990 grandes empreendimentos relacionados à pecuária, mineração e construção de usinas hidrelétricas. Também se deslocaram para a região grandes levas de migrantes sem-terra. A Amazônia Oriental ao longo desses anos transformou-se em um imenso cenário de ocupação territorial marcado por uma história de destruição, mas também com história de resistência, de revolta, de protesto e de sonhos em meio à luta pela terra (MARTINS, 1996).

Segundo os dados do INCRA (2018), o Brasil tem 9.478 projetos de assentamentos de reforma agrária, com 1.349.689 famílias assentadas. 0 Pará concentra 22,8\% desse total, com 308.173 famílias assentadas, sendo que 99.256 famílias estão assentadas no Sul e Sudeste do Pará, distribuídas em 515 projetos de assentamentos de reforma agrária (INCRA, 2018).

Executados especificamente na microrregião do município de Marabá e municípios em seu entorno, os projetos PRONERA destinavam-se ao atendimento dessa população beneficiária da política de reforma agrária, tendo inicialmente como proponente o Campus Universitário de Marabá, da UFPA, transformado em 2013 na sede da Universidade Federal do Sul e Sudeste do Pará. 
Os projetos executados via PRONERA pelo Campus Universitário de Marabá - UFPA, no período de 1998 a 2011, foram os seguintes: Alfabetização de Jovens e Adultos (19992000); escolarização de Monitores de Alfabetização em curso de elevação de escolaridade na educação básica com Ensino Fundamental, 5ª a 8a Séries (1999-2000); formação de professores com curso de Ensino Médio Magistério (2001-2004); elevação de escolaridade na Educação de Jovens e Adultos, anos iniciais do Ensino Fundamental (2003-2006); formação de Ensino Médio Técnico-Profissional em Agropecuária com Ênfase em Agroecologia, com duas turmas (2003-2007 e 2005-2009); formação acadêmica no ensino superior, com Curso de Graduação em Agronomia (2003-2009), Curso de Graduação em Letras (2005-2011), Curso de Graduação em Pedagogia (2005-2011) e Curso de Especialização em Agricultura Familiar Camponesa e Educação do Campo - Residência Agrária (2005-2007). São projetos no âmbito da educação básica e ensino superior realizados por meio da parceria entre a universidade e o Movimento dos Trabalhadores Rurais Sem Terra (MST), a Federação dos Trabalhadores na Agricultura (FETAGRI), a Escola Família Agrícola de Marabá (EFA) e a Comissão Pastoral da Terra (CPT).

Em meio às experiências dos projetos vinculados ao PRONERA, da tradição das conjugações das lutas sociais para ampliar o acesso a direitos e da busca pela constituição de redes de parceiros que fortalecessem tais lutas, nasceu o Fórum Regional de Educação do Campo do Sul e Sudeste do Pará (FREC), uma entidade composta pelos movimentos sociais, ONGs, universidades, secretarias municipais de educação e organismos governamentais ligados às questões ambientais e agronômicas. A existência do fórum materializou-se por meio da formação de uma coordenação geral composta por professores da universidade e membros dos movimentos sociais; das atividades de grupos de trabalho voltados a discussões temáticas que envolviam educação e questões agrárias e ambientais; das reuniões em plenária geral para debater pautas emergentes sobre as mesmas temáticas; e na realização bianual das conferências regionais de Educação do Campo - como eventos realizados com a participação de representantes de movimentos sociais, redes municipais de educação, universidades e entidades parceiras do FREC.

Em 2008, a UFPA foi incluída no convite feito pelo Ministério da Educação e Cultura (MEC) para participar do primeiro edital para realização do curso de Licenciatura em Educação do Campo. No bojo das experiencias engendradas via o PRONERA, duas ocorrências foram fundamentais para a constituição e amadurecimento da proposta de curso apresentada originalmente como Licenciatura Plena em Educação do Campo (LPEC) pelos atores do Sudeste do Pará. A primeira ocorrência foi a experiência em educação básica e com a Pedagogia da Alternância vivenciada através das duas primeiras turmas do projeto de Curso de Ensino Médio Técnico-Profissional em Agropecuária com Ênfase em Agroecologia, desenvolvidas junto à Escola Família Agrícola de Marabá (EFA) e à Federação dos Trabalhadores na Agricultura do Pará (FETAGRI), coordenados por professores dos colegiados de Curso da Pedagogia e Agronomia, do Campus Universitário de Marabá (UFPA). Essa experiência foi importante para a configuração da LPEC não só com relação aos aprendizados advindos da práxis pedagógico-curricular com ensino fundamental e médio desenvolvido através da Pedagogia da Alternância, mas principalmente quanto à sua realização gestada por meio de uma rede político-pedagógica envolvendo movimentos sociais, universidade, ONGs e organismos e secretarias governamentais. Essa mesma 
rede, em perspectiva ampliada, materializou na regição a criação e funcionamento do Fórum Regional de Educação do Campo do Sul e Sudeste do Pará (FREC) e constituiuse a segunda ocorrência determinante da elaboração da proposta, criação do curso e composição do quadro docente da LPEC e do que veio a ser a Faculdade de Educação do Campo, posteriormente.

A proposta de curso foi elaborada por uma equipe interdisciplinar, incluindo membros do fórum e professores da universidade, em especial aqueles que haviam atuado como formadores e coordenadores dos projetos executados via o PRONERA. Em seguida, a proposta de curso foi apresentada ao FREC e, no ano de 2008, submetida às instâncias superiores da UFPA, como curso regular do quadro de oferta permanente do Campus Universitário de Marabá - UFPA, sendo aprovada.

O Curso de Licenciatura em Educação do Campo do Campus de Marabá começou a ser implementado no ano de 2009, inicialmente contando com um quadro de professores colaboradores, das Faculdades de Agronomia, Pedagogia e Letras, faculdades envolvidas no desenvolvimento dos projetos vinculados ao PRONERA.

Neste mesmo ano, novamente por articulação e interlocução do FREC reivindicando junto à administração da universidade vagas de docentes para o curso, a reitoria da UFPA incluiu o curso LEDoC no Programa de Apoio a Planos de Reestruturação e Expansão das Universidades Federais (REUNI), criado pelo Ministério da Educação (MEC), através do Decreto $n^{\circ}$ 6.096/2007. O REUNI visava a promover a expansão do ensino superior, ampliando o número de vagas para estudantes e promovendo concurso para professores. Os professores da universidade envolvidos com o novo curso se assumiram publicamente como críticos ao REUNI, alegando que o programa propunha a ampliação do acesso sem garantir a ampliação dos recursos que assegurassem a manutenção adequada do custo aluno-ano e a ampliação da infraestrutura das universidades de modo condizente às suas necessidades. Entretanto, em debate no fórum, os membros de movimentos sociais defenderam que existiam elementos da realidade que apontavam para necessidade urgente em assegurar a formação de professores de Educação Básica para atender demandas das escolas das comunidades rurais da região.

Do ponto de vista de nossa realidade regional, ao olharmos para a situação da educação do Campo, as assimetrias se intensificam, pois nas escolas do campo registradas no último censo do INEP em 2009, apenas 3\% das escolas de $1^{\text {a }}$ a $5^{\text {a }}$ série contavam com professores com formação em nível superior e/ou licenciatura, com relação ao ensino médio 45\% das escolas contam com professores habilitados em nível superior e/ou com licenciatura, reforçando a imensa demanda pela formação de educadores do campo. [...] formando professores-educadores aptos para atuarem nessas escolas, haja vista a ausência de profissionais minimamente formados. (UNIFESSPA, 2014, p. 5).

Pesou ainda na decisão em integrar o REUNI a ponderação dos membros do fórum em buscar alternativas para dar continuidade ao processo histórico de desenvolvimento da Educação do Campo na região. Por meio do REUNI foram garantidas as primeiras vagas de concurso público para formação do quadro de professores efetivos do Curso de Licenciatura em Educação do Campo do Campus de Marabá, que passou a integrar a Faculdade de Educação, juntamente com o Curso de Pedagogia. 
Em 2013, em meio à política federal de expansão do ensino superior, foi criada a Universidade Federal do Sul e Sudeste do Pará (UNIFESSPA) a partir do desmembramento da Universidade Federal do Pará (UFPA), através da Lei nº12.824/2013. Em meio a esse processo, em decorrência de uma avaliação e decisão estratégica tomada pelos professores do Curso de Licenciatura em Educação do Campo, foi criada a Faculdade de Educação do Campo (FECAMP0). Além da licenciatura, a faculdade passou a abrigar duas turmas dos cursos de especialização em Currículo e Educação do Campo e Educação do Campo e Agroecologia, vinculadas ao Programa Residência Agrária (PRONERA/INCRA/MDA).

Naquele mesmo ano, a UNIFESSPA aderiu ao edital do Programa de Apoio à Formação Superior em Licenciatura em Educação do Campo (PROCAMPO) e o Curso de Licenciatura em Educação do Campo da FECAMPO passou a realizar processo seletivo de turmas com 120 discentes por três anos seguidos (2014, 2015 e 2016). Os recursos provenientes do programa ajudaram a garantir alojamento, material didático e alimentação aos alunos dessas turmas até janeiro e fevereiro de 2017.

A forma de ingresso dos educandos ao curso de LEDoC da UNIFESSPA vem sendo realizada desde o ano de 2009 via Processo Seletivo Especial (PSE), que acontece em duas etapas, sendo a primeira uma prova com quarenta questões de múltipla escolha sobre conhecimentos gerais referentes aos conteúdos programáticos do ensino médio e mais uma redação; já segunda etapa é qualitativa e conta realização de entrevistas presenciais em que é verificada a relação do mesmo com o curso. Entre 2009 e 2015, o PSE da LEDoC UNIFESSPA foi coordenado pelo Centro de Processos Seletivos (CEPS), órgão pertencente à Universidade Federal do Pará (UFPA). A partir de 2016, o processo seletivo passou a ser coordenado pelos próprios docentes do curso, com o processo planejado e executado sob a responsabilidade de uma comissão interdisciplinar. No gráfico abaixo, é possível observar a demanda de inscritos no PSE LEDOC no período de 2010 a 2017.

Gráfico 2- Quantitativo de inscritos nos PSE LEDOC UNIFESSPA (2010-2017)

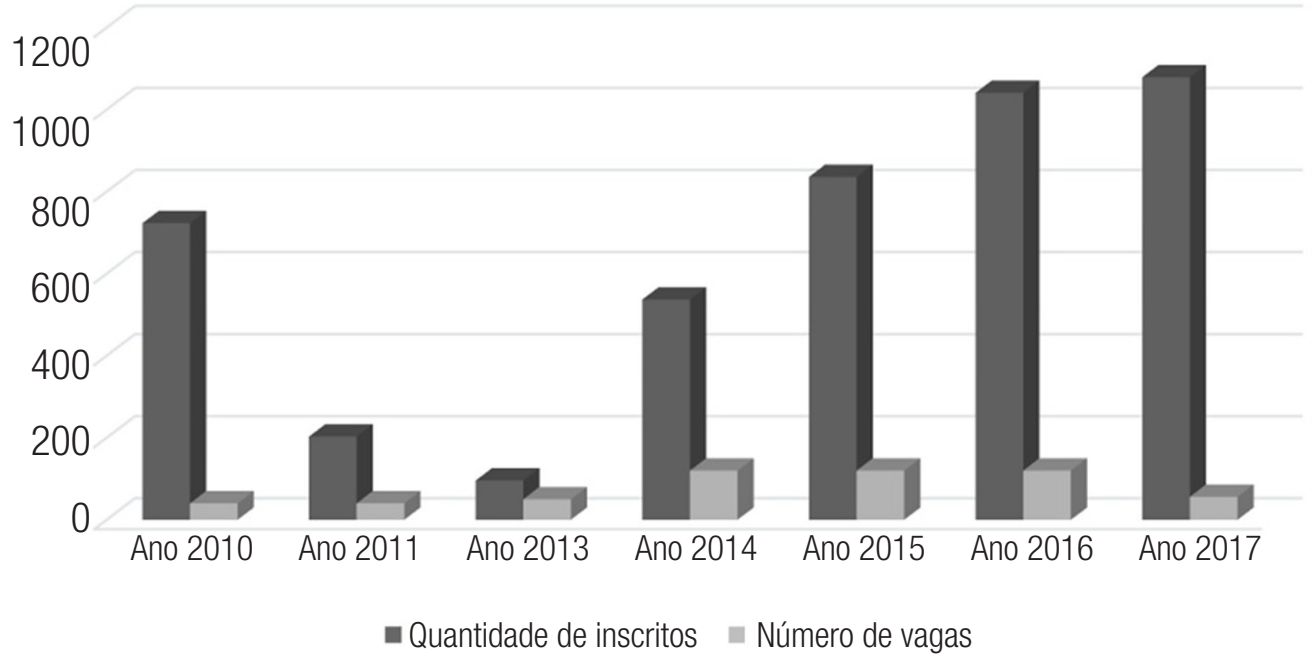

Fonte: FECAMPO, 2017. 
0 curso tem a possibilidade de ofertar até 60 vagas anualmente, respeitando o regulamento de graduação da instituição. Em caráter excepcional, entre os anos de 2014 a 2016 foram ofertadas 120 vagas para atender ao edital do PROCAMPO (Edital n 2/2012), que previa o ingresso de 120 alunos ano ao longo de três anos (ver gráfico 02). Como o curso já estava institucionalizado desde 2009, em 2017 a UNIFESSPA voltou a realizar o processo seletivo para ingresso de discentes com oferta de 60 vagas anualmente.

Gráfico 3- Número de Matrículas Efetivadas na LEDoC UNIFESSPA (2009-2017)

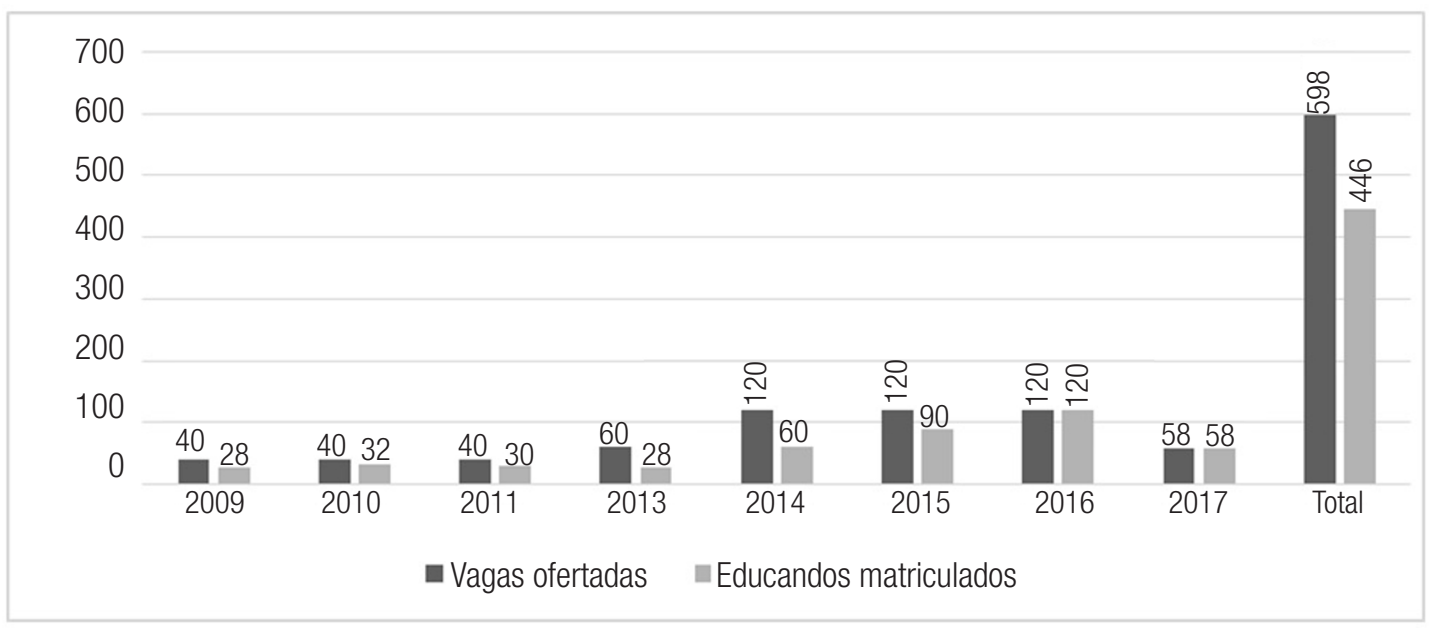

Fonte: FECAMPO, 2017.

0 curso realizado no Sudeste do Pará atende educandos oriundos de comunidades rurais de diferentes municípios paraense e do estado do Maranhão. Entre eles, estão os municípios localizados bem distantes da sede do curso, como Belém, Irituia, Santa Barbara do Pará, Concordia do Pará e Igarapé Mirim, no Nordeste do estado, e Soure e Anajás, da Mesorregião do Marajó. Esses dois últimos localizados a mais de 500km de distância de Marabá.

Ao assumir a interdisciplinaridade como fundamento de sua proposta curricular, o curso de Licenciatura em Educação do Campo da FECAMPO/UNIFESSPA está estruturado em quatro áreas de conhecimento, tendo o exercício e a busca da interdisciplinaridade como princípios para a formação dos educandos. As quatro áreas específicas são as de Ciências Humanas e Sociais (CHS), Ciências Agrárias e da Natureza (CAN); Letras e Linguagens (LL) e Matemática (MAT), tendo como disciplinas de referência Geografia, História e Sociologia, no caso da área de conhecimento das Ciências Humanas e Sociais; Física, Química e Biologia, para as Ciências Agrárias e da Natureza; Português, Literatura e Redação, para as Letras e Linguagens e Matemática para área de Matemática, almejandose assim que os educandos estejam habilitados a trabalhar os conteúdos e construir currículos que deem conta dos $3^{\circ}$ e $4^{\circ}$ Ciclos do Ensino Fundamental e o Ensino Médio (UNIFESSPA, 2014, p. 5). 
Figura 3- Mapa de distribuição Regional de Educandos da LEDoC UNIFESSPA (2016)

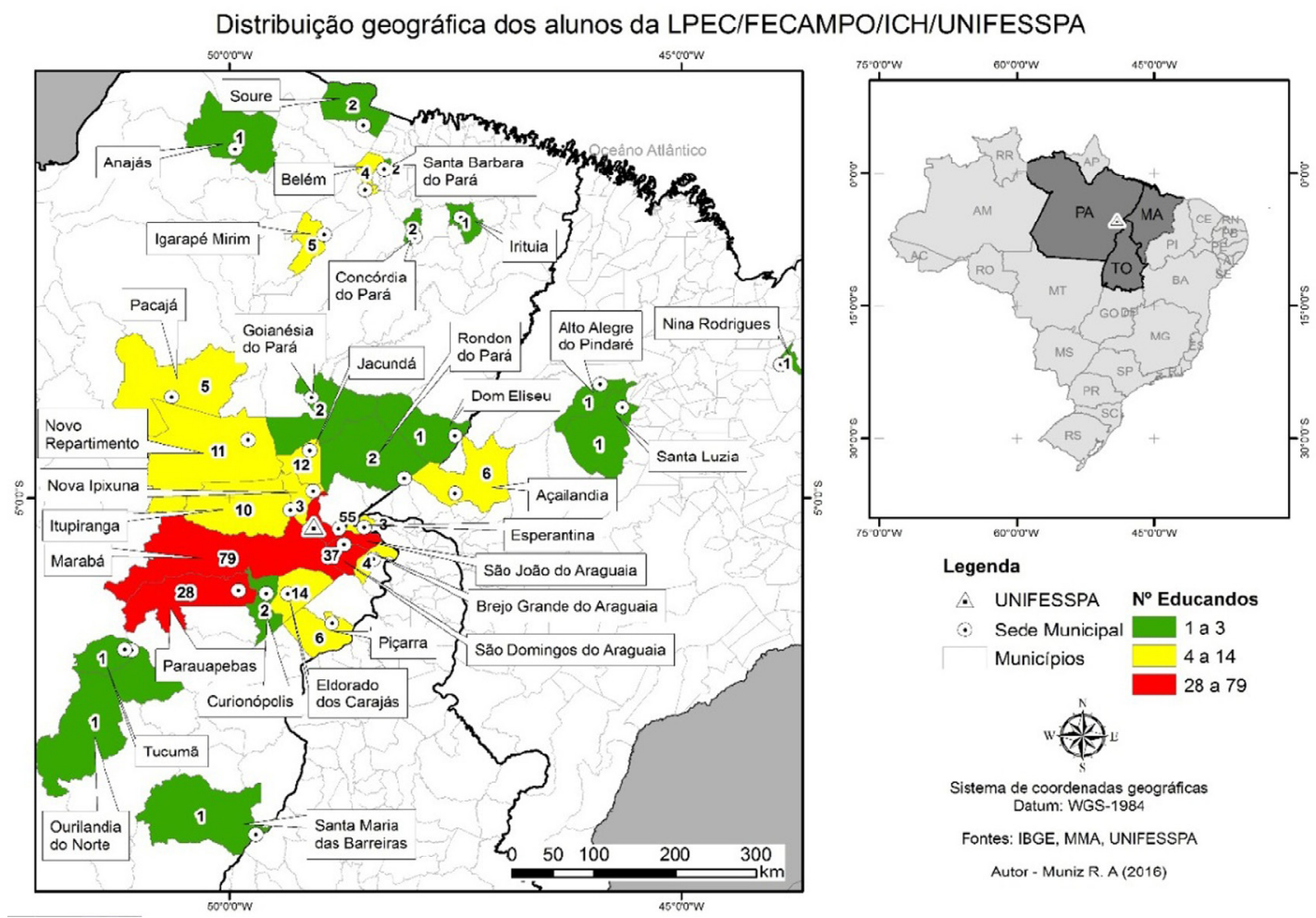

Fonte: FECAMP0, 2017

Dessa forma, a organização curricular do curso busca dar conta de "contemplar todas as áreas de conhecimento previstas para a docência multidisciplinar, garantindo estudos básicos para o conjunto dos estudantes em cada uma delas", em acordo com as exigências dos editais da SECADI/MEC (UNIFESSPA, 2014, p. 21). Do mesmo modo a formação:

[...] se faz através de núcleos de estudo que tentam contemplam e articular estes eixos de formação, [...] de modo que os estudantes-educadores possam vivenciar na prática de sua formação a lógica metodológica para a qual estão sendo preparados. (UNIFESSPA, 2014, p. 20).

A formação é articulada entre atividades presenciais (Tempo Escola) e atividades orientadas não-presenciais (Tempo Comunidade), o primeiro, caracterizado como momento de estudos teóricos e debates, o segundo, marcado por pesquisas de campo, estudos independentes e práticas pedagógicas planejadas coletivamente e realizadas pelos educandos quando retornam às suas comunidades. Além de assegurar o campo de estágios curriculares que incluam experiências de exercício profissional, a organização do processo pedagógico alternado entre tempos-espaços escola e comunidade visa a garantir a formação docente com "ênfase na pesquisa, como processo desenvolvido ao longo do 
curso e integrador de outros componentes curriculares, culminando na elaboração de um trabalho monográfico com defesa pública” (UNIFESSPA, 2014, p. 20).

A formação acadêmica desencadeada por esse processo tenta fomentar um aprendizado teórico-metodológico e uma postura docente pautada pela:

[...] necessária dialética entre educação e experiência, garantindo um equilíbrio entre rigor intelectual e valorização dos conhecimentos já produzidos pelos educadores (camponeses) em suas práticas educativas e em suas vivências socioculturais (sic). (UNIFESSPA, 2014, p. 20).

0 histórico das iniciativas em Educação do Campo no Sudeste do Pará deixa claro como o desenvolvimento dos projetos PRONERA e da LEDoC, para além da busca em assegurar o direito de acesso ao ensino superior aos povos do campo, foi também um processo transformador para própria universidade, com criação de novos cursos e novas estruturas institucionais. No caso da UNIFESSPA, a criação da Faculdade de Educação do Campo.

Além da criação da LEDoC no Campus Universitário de Marabá (UFPA), a rede político-pedagógica constituída através do Fórum Regional de Educação do Campo do Sul e Sudeste do Pará (FREC) também foi responsável pela mobilização e debates que resultaram na criação do Campus Rural de Marabá do Instituto Federal de Educação, Ciência e Tecnologia do Pará (CRMB-IFPA), criado em 2007 e instalado dentro do Assentamento de Reforma Agrária “26 de Março”, vinculado ao Movimento dos Trabalhadores Rurais Sem Terra (MST). O CRMB-IFPA ofertaria também o curso da LEDoC, vinculado ao PROCAMPO (Editais SECAD/MEC/2008 e SECAD/MEC/2009).

Outras turmas da LEDoC também foram criadas em campus da Universidade Federal do Pará (UFPA) em diferentes municípios, inspiradas no projeto pedagógico curricular e na experiência do curso realizado pela Faculdade de Educação do Campo (FECAMPOUNIFESSPA) em Marabá. Essas turmas também passaram a integrar o quadro de cursos da universidade de modo permanente e foram a base da criação de novas Faculdades de Educação do Campo na UFPA: a Faculdade de Educação do Campo do Campus Cametá (2013) e Faculdade de Educação do Campo de Campus Abaetetuba (2017).

\section{Conclusão}

A criação e consolidação da territorialização dos cursos do LEDoC no Brasil e no Pará ilustram como, mais que debater o direito à educação, as ações desencadeadas a partir da rede político-pedagógica constituída pelo Movimento de Educação do Campo possibilitaram o debate e ampliação do conceito de direito e educação, fomentando ressignificações de políticas públicas e programas de governo segundo a perspectiva e demandas das populações do campo.

Essas transformações têm efeitos sobre as definições do papel da educação escolar e da escola, de modo que ela seja percebida como espaço-sujeito coletivo comprometido com a construção de conhecimentos voltados à compreensão e transformação da realidade, aberta às mudanças sociais e que consiga acompanhá-las, entrelaçando saber universal e saber local, considerando as 
experiências de vida discentes e investindo nesses para que se tornem sujeitos críticos, criativos e solidários. (UNIFESSPA, 2014, p. 13).

Essas transformações alcançam também os professores dos cursos. No sudeste do Pará, esse processo manifesta-se em especial como decorrência do tempo comunidade, quando os professores universitários realizam visitas às comunidades e famílias camponesas e fazem o acompanhamento pedagógico das atividades realizadas pelos educandos, visando também a conhecer melhor a realidade socioambiental, a cultura camponesa e as questões agrárias da região. Esse é um processo que certamente contribui também para formação em contínuo dos próprios professores, formação em e no movimento do fazer educação escolar e da luta pela terra, na e pela práxis docente. Resulta no enriquecimento e aprofundamento da compreensão teórica sobre a realidade social, a educação e a escola e na requalificação e ampliação dos saberes pedagógicos e melhoria constante do trabalho docente, algo fundamental aos professores que atuam na formação de professores.

Por um outro lado, o processo de ampliação massiva da oferta dos Cursos de Licenciatura em Educação do Campo e institucionalização das ações em Educação do Campo, por meio da sua inclusão na estrutura das secretarias de educação de estados e municípios, têm colocado às universidades e aos movimentos sociais preocupação de como assegurar e consolidar as conquistas pedagógicas, epistêmicas e acadêmicas já alcançadas sem perder a identidade política original, sem se distanciar da luta pela terra e sem extinguir o protagonismos dos movimentos sociais do campo.

Entre os dados apresentados neste trabalho a partir da análise do Censo da Educação Superior (INEP, 2017), constatar a existência de turmas da LEDoC em modalidade de Educação a Distância inevitavelmente levam a questionamentos sobre suas propostas, atividades e práticas pedagógicas, principalmente no que se refere à alternância pedagógica (Tempo Comunidade e Tempo Escola) que acontece nos cursos de LEDoC não enquadrados nesta modalidade. Em especial porque em sua origem o curso objetiva promover uma formação embasada na pesquisa e estudo da memória, saberes, valores, costumes, bem como práticas sociais e produtivas dos sujeitos do campo e dos diferentes sujeitos atuantes no meio rural, valorizando os diferentes saberes dos povos e comunidades rurais como possibilidade de produção conjunta do conhecimento, o que requer plena presença nas comunidades e na universidade.

Por fim, neste momento político pelo qual passa o país, em que estão colocadas em risco conquistas históricas do Movimento Nacional de Educação do Campo, ganham importância pesquisas que possam subsidiar a elaboração de reflexões acerca dos processos de institucionalização da Educação do Campo no país. São importantes as pesquisas focando as historicidades, estratégias constituídas, avanços e contradições que marcam a existência das diversas iniciativas pedagógicas espalhadas pelo país, permitindo analisar os processos formativos que tal institucionalização materializa e como estes têm sido desenvolvidos assegurando aos povos do campo, para além do direito à escola, a afirmação da condição de sujeitos do campo como sujeitos de direitos, sujeitos de políticas, sujeitos pedagógicos e sujeitos de conhecimento, em consonância com aquilo que é defendido pela luta e princípios do Movimento Nacional por uma Educação do Campo. 


\section{Referências}

BRASIL. Decreto n $^{\mathbf{7}}$ 7.352, de 04 de dezembro de 2010. Dispõe sobre a política de Educação do Campo e o Programa Nacional de Educação na Reforma Agrária. Brasília: Imprensa Nacional, 2010.

BRASIL. Saberes da Terra. Programa Nacional de Educação de Jovens e Adultos integrada com qualificação social e profissional para agricultores (as) familiares. Brasília: Imprensa Nacional, 2005.

FECAMPO. Faculdade de Educação do Campo. Relatório técnico de prestação de contas projeto de ensino: implantação do curso de licenciatura em Educação do Campo 2014 a 2016. Marabá: FECAMPOUNIFESSPA, 2017. 103 p. Não publicado.

FONEC. Fórum Nacional de Educação do Campo. Carta de criação do Fórum Nacional de Educação do Campo. Brasília: [s. n.], 2010.

INCRA. Instituto Nacional de Colonização e Reforma Agrária. Números da reforma agrária. Brasília: Incra, 2018. Disponível em: http://www.incra.gov.br/reforma-agraria/questao-agraria/reforma-agraria. Acesso em: 24 abr. 2019.

INEP. Instituto Nacional de Estudos e Pesquisas Educacionais Anísio Teixeira. Censo da educação superior: notas estatísticas - 2017. Brasília, DF: MEC, 2017.

IPEA. Instituto de Pesquisa Econômica Aplicada. Relatório da II pesquisa nacional sobre a educação na reforma agrária. Brasília: IPEA, 2015.

MARTINS, José de Souza. Fronteira: a degradação do Outro nos confins do humano. São Paulo: Hucitec, 1996.

MOLINA, Mônica Castagna; HAGE, Salomão Mufarrej. Riscos e potencialidades na expansão dos cursos de licenciatura em educação do campo. Revista Brasileira de Política e Administração da Educação, Goiânia, v. 32, n. 3, p. 805-828, set./dez. 2016.

MUNARIM, Antônio. Movimento nacional de educação do campo: uma trajetória em construção. In: REUNIÃO ANUAL DA ANPED, 31., 2008, Caxambu., Anais... Caxambu: ANPEd, 2008. GT3 - Movimentos Sociais E Educação.

ROCHA, Eliene Novaes. Das práticas educativas às políticas públicas: tramas e artimanhas pela educação do campo. 2013. Tese (Doutorado em educação) - Faculdade de Educação, da Universidade de Brasília, Brasília, 2013.

SILVA, Maria do Socorro. As práticas pedagógicas das escolas do campo: a escola na vida e a vida como escola. 2009. Tese (Doutorado em educação). Centro de Educação, Universidade Federal de Pernambuco, Recife, 2009.

SILVA, Maria do Socorro. Da raiz à flor: produção pedagógica dos movimentos sociais e a escola do campo. In: MOLINA, Mônica Castagna (Org.). Educação do campo e pesquisa: questões para reflexão. Brasília: Nead, 2006. p. 66-93. 
UNIFESSPA. Universidade Federal do Sul e Sudeste do Pará. Projeto pedagógico do curso licenciatura em educação do campo. Marabá: Unifesspa, 2012.

UNIFESSPA. Universidade Federal do Sul e Sudeste do Pará. Projeto pedagógico do curso licenciatura em educação do campo. Marabá: Unifesspa, 2014.

Recebido em: 29.05.2019

Aprovado em: 15.08.2019

Evandro Costa de Medeiros é professor adjunto da Universidade Federal do Sul e Sudeste do Pará - Marabá. Mestre em educação pela Universidade Federal de Santa Catarina (2002), e graduado em pedagogia pela Universidade Federal do Pará (1998). Doutorando do Programa de Pós-Graduação em Educação da Universidade Federal da Paraíba (UFPB).

Glaucia de Sousa Moreno é professora assistente da Universidade Federal do Sul e Sudeste do Pará - Marabá. Mestre em agriculturas familiares e desenvolvimento sustentável (2011), graduada em agronomia pela Universidade Federal do Pará (2008). Doutoranda do Programa de Pós-Graduação em Educação Cientifica e Tecnológica da Universidade Federal de Santa Catarina.

Maria do Socorro Xavier Batista é professora titular da Universidade Federal da Paraíba, no Departamento de Educação do Campo. Tem graduação em pedagogia pela Universidade Federal da Paraíba (1978), mestrado em sociologia pela Universidade Federal da Paraíba (1983) e doutorado em sociologia pela Universidade Federal de Pernambuco (2000). 